TI 2011-005/3

Tinbergen Institute Discussion Paper

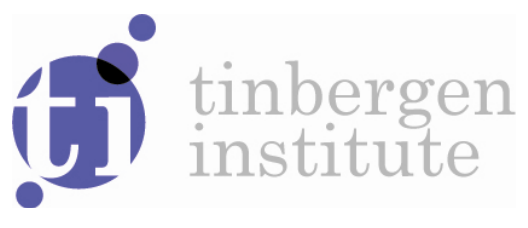

The Willingness To Pay For Quality Aspects Of Durables: Theory And Application To The Car Market

\author{
Ismir Mulalic' \\ Jan Rouwenda/2
}

' University of Copenhagen, Denmark;

2 VU University Amsterdam, Tinbergen Institute, the Netherlands. 
Tinbergen Institute is the graduate school and research institute in economics of Erasmus University Rotterdam, the University of Amsterdam and VU University Amsterdam.

More TI discussion papers can be downloaded at http://www.tinbergen.nl

Tinbergen Institute has two locations:

Tinbergen Institute Amsterdam

Gustav Mahlerplein 117

1082 MS Amsterdam

The Netherlands

Tel.: +31(0)205251600

Tinbergen Institute Rotterdam

Burg. Oudlaan 50

3062 PA Rotterdam

The Netherlands

Tel.: +31(0)10 4088900

Fax: +31(0)104089031

Duisenberg school of finance is a collaboration of the Dutch financial sector and universities, with the ambition to support innovative research and offer top quality academic education in core areas of finance.

DSF research papers can be downloaded at: http://www.dsf.nl/

Duisenberg school of finance

Gustav Mahlerplein 117

1082 MS Amsterdam

The Netherlands

Tel.: +31(0)20 5258579 


\title{
The willingness to pay for quality aspects of durables: theory and application to the car market
}

Ismir Mulalic

Dept. of Economics

University of Copenhagen

Øster Farimagsgade 5, Building 26

1353 Copenhagen $\mathrm{K}$

Denmark

e-mail: Ismir.mulalic@econ.ku.dk and

Jan Rouwendal

Dept. of Spatial Economics

VU University

De Boelelaan 1105

$1081 \mathrm{HV}$ Amsterdam

The Netherlands

e-mail: jrouwendal@,feweb.vu.nl

This version: December 24, 2010

Keywords: durable goods, willingness to pay, hedonic analysis, nonparametrics, car market.

JEL codes: C14, D46, L62, L68.

\begin{abstract}
Conventional hedonic analysis measures willingness to pay for attributes on the basis of marginal fixed costs. We argue that in many cases variable costs are also affected by these attributes and that this should be taken into account. We develop a simple model to show that the marginal willingness to pay for a quality attribute has to be equal to the full marginal cost, which includes marginal fixed as well as variable costs. The model is applied to Danish data on car ownership and use. We use a nonparametric estimation procedure to estimate hedonic price functions for fixed and variable costs. We recover each consumer's marginal willingness to pay, the marginal fixed costs, and the marginal variable costs for car attributes using first-order conditions for utility maximization. We show that the marginal fixed and variable costs have the same (positive) sign and that both contribute substantially to the marginal willingness to pay. Estimation results suggest that marginal variable costs are on average about $20 \%$ of the full marginal costs. Finally, we estimate the distribution of the marginal rate of substitution between quality attributes and variable costs, which can be interpreted as a structural parameter, and we investigate how this marginal rate of substitution varies with household characteristics.
\end{abstract}





\section{Introduction}

This paper examines consumer choice behavior for durables taking into account dependence of both the fixed and the variable costs associated with the durable on quality aspects of the durable. The costs associated with durable goods often depend on the use made of the good. That is, in addition to the fixed cost there are non-negligible variable costs. In many cases fixed as well as variable costs are functions of the characteristics of the good. For instance, the engine power of a car is related to its fuel use. Cars are certainly not the only example of this phenomenon. Many hedonic studies have shown that the volume of a house is related to its price or rent (the fixed cost), but volume also has consequences for the variable costs associated with living in the house as heating a larger house requires more fuel. The marginal willingness to pay for space should therefore be computed by taking into account the increase in fixed as well as variable costs implied by an additional cubic meter. Nevertheless, most studies on the willingness to pay for housing characteristics concentrate exclusively on house prices, thereby ignoring variable costs (see for instance, Sheppard, 1999). The example just given is not exceptional. Indeed, many characteristics of housing - the presence and size of a garden, the number of bathrooms, et cetera - should be expected to affect the costs of living in the house: maintenance of the garden, keeping the bathrooms clean, et cetera. Other examples of characteristics of durables that affect variable as well as fixed costs are easy to find.

Although most studies have ignored variable costs when studying the demand for durables there are notable exceptions to this rule. The trade-off between fixed and variable costs of energy using durables has been studied by Hausman (1979) and Dubin and McFadden (1984). Hausman (1979) computed the discount rate implied by the choices of the consumers, and Dubin and McFadden (1984) showed that, in reaction to increasing fuel prices, consumers switch to more fuel efficient varieties and decrease the use made of the durable to some extent. However, the examples mentioned above show that there is not always a trade-off between fixed and variable costs. Fuel efficiency as a cause of higher fixed and lower variable costs appears to be a special case. Many other characteristics affect fixed and variable costs in the same direction. More volume of a house implies higher costs of heating as well as a higher house price. More engine power of a car means higher fixed and variable costs. Making a car safer - for those inside it - often means that its weight increases, which implies (all else equal) that fuel costs will be higher. More cabin space implies that the car will be more voluminous and (again, all else equal) this will increase fuel costs. We will 
document the positive relationship between fixed and variable costs for car characteristics later in the paper.

This paper develops a simple model of consumer choice behavior for durables in which fixed as well as variable costs are functions of the characteristics of the durable. We allow for the possibility that both cost functions are increasing in particular characteristics. A special feature of the model is that the quality characteristics may appear in the utility function. Consumers derive utility from housing or car characteristics in a direct way, something that is less likely in the case of fuel efficiency. We then derive a simple relationship between the willingness to pay for these characteristics and the fixed and variable costs. The marginal willingness to pay for a quality characteristic has to be equal to the full marginal cost, which includes marginal fixed as well as variable costs. The conventional approach in housing economics, where marginal willingness to pay is set equal to marginal fixed costs corresponds to the special case in which the characteristic has no impact on variable cost. The situation studied by Hausman (1979) and Dubin and McFadden (1984) corresponds to another special case in which the characteristic under study does not affect preferences directly. We show that in the case studied by these authors we need a trade-off between both types of costs for an interior solution. Moreover, we demonstrate that there can be an interior solution with positive marginal fixed as well as variable costs in cases where the characteristic has a direct positive effect on the consumer's utility.

The model is applied to Danish data on car ownership and use. We analyze an unusually rich dataset that informs us about car prices, car costs and car use. This allows us to estimate hedonic price functions for fixed as well as variable costs. We implement our model and compare the full marginal willingness to pay with that implied by analyzing the fixed cost only and find important differences. Moreover, we show that a special version of the model motivates a structural interpretation of our results as the marginal rate of substitution between characteristics and variable costs and investigate how this marginal willingness to pay varies with household characteristics.

The paper proceeds as follows. The next section introduces the theoretical model of consumer choice behavior for durables. Section 3 provides information on the data employed; Section 4 presents the estimation strategy and the empirical results; Section 5 reports on a further investigation of preferences; and Section 6 concludes. 


\section{The model}

This section discusses the model that underlies the empirical work that follows. We introduce quality in the standard (textbook, two good) microeconomic models of consumer behavior in a very general way: one of the two goods is quality differentiated and the consumer has preferences over quality. The differentiated good has a constant unit price, referred to as its variable cost and a fixed cost. Both depend on the quality level chosen by the consumer. In subsection 2.1 the model is introduced, 2.2 analyzes quality choice. In 2.3 we briefly discuss the hedonic fixed cost function that corresponds with market equilibrium and in 2.5 we consider the structural interpretation of the empirical results.

\subsection{Preliminaries}

We consider a household that derives utility $u$ from car kilometers, ${ }^{1}$ denoted as $q$, the quality of the car, $k$, and other goods $x$ (which are treated as a single composite):

$u=u(x, q, k)$.

In what follows we usually treat $k$ as a scalar for expositional simplicity, but most of the analysis remains unchanged when it is a vector of characteristics. Examples of relevant car quality attributes are engine power, transmission system and capacity. The utility function is increasing in its three arguments and its indifference curves are convex. Since our empirical application below is about cars, we will henceforth use this example for concreteness, but it should be kept in mind that the model has more general applicability. Car kilometers $q$ and other goods $x$ are conventional goods in the sense that they are available in continuous amounts at fixed unit prices. The price of car kilometers equals variable car costs $p$ while the price of the composite good is normalized to 1. Car quality is different from the other goods: it is an intrinsic property of the car owned by the household and as such it affects fixed as well as variable costs. The budget constraint is:

$x+p(k) q=y-f(k)$

where $p$ denotes the variable cost (per kilometer) of car use, and $f$ the (annual) fixed cost. Both depend on quality. The fixed cost should be interpreted as user cost, that is as the sum of fixed maintenance costs, taxes, and the difference between the value of the car at the beginning of the year and the present value of its price at the end of that year (i.e. depreciation).

\footnotetext{
${ }^{1}$ Although we realize that travel demand is in many cases derived from the demand for other goods, we follow the bulk of literature by treating car kilometers as a conventional good.
} 
Conditional upon the choice of $k$, the maximization of (2.1) subject to (2.2) is the textbook utility maximization problem that under standard conditions can be solved to derive the demand equations for $q$ and $x$. The former can be expressed as:

$q=q(y-f(k), p(k), k)$.

Assumption 1. Demand for car kilometers is normal, that is, the demand function $q(y-f(k), p(k), k)$ is increasing in $y-f(k)$.

Economic theory (the Slutsky theorem) now implies that the demand for car kilometers will be decreasing in the variable car cost $p$.

The sign of the effect of quality on the demand for car kilometers can be derived from a second assumption that refers to the relationship between a change in quality, $\Delta k$, and a change in the amount of the composite consumption, $\Delta x$, that compensates the consumer for the change in $k$, while keeping $q$ constant. The value of $\Delta x$ is determined by the initial values of $x, q$ and $k$, and by the change in $k, \Delta k$. Since the first three variables determine initial utility, $u$, we can write $\Delta x$ alternatively as a function of $u, q$ and $k$ and $\Delta k$. The variable $\Delta x$ is implicitly defined by the following equation:

$u(x-\Delta x(u, q, k, \Delta k), q, k)=u(x, q, k+\Delta k)$.

Assumption 2. For $k>0, \Delta x(u, q, k, \Delta k)$ is an increasing function of $q$.

This assumption states that a consumer who drives more kilometers attaches a higher value to car quality in the sense that she is willing to give up more of the composite good in exchange for a higher quality of the car. The assumption is illustrated in Figure 1. This figure shows two indifference curves in $q, x$-space. Both indifference curves refer to the same level of utility, $u^{*}$, but to different level of car quality. Since car quality is valued positively by the consumer, the lower indifference curve in $q, x$-space refers to the higher level of car quality. For a given number of car kilometers, the value measure $\Delta x$ defined above is the vertical difference between the two indifference curves. 
Figure 1. The value of car quality

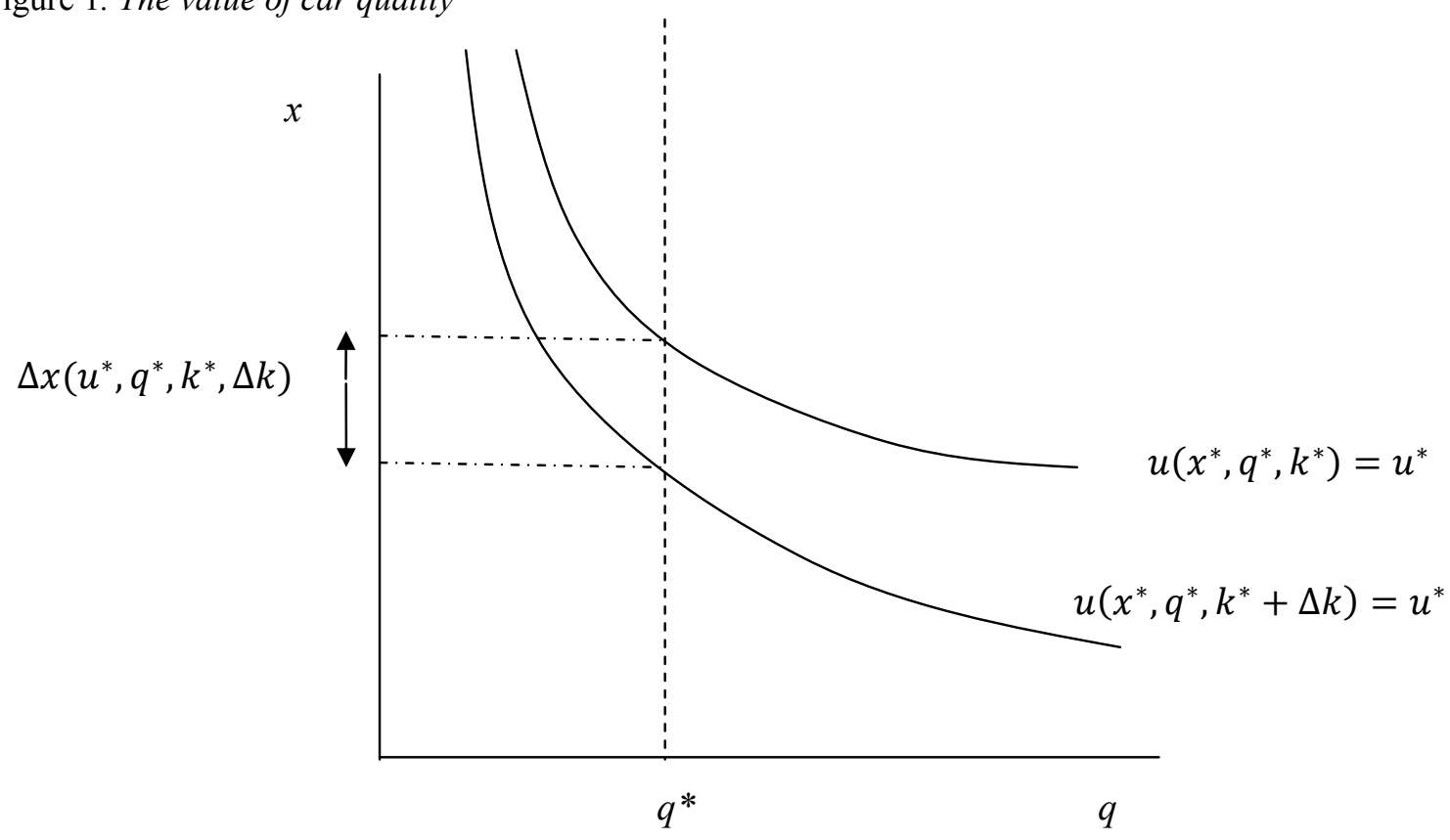

Assumption 2 implies that, for a given value of $q$, the indifference curve gets steeper when car quality increases. It follows that the demand for car kilometers is an increasing function of car quality. That is, if fixed and variable cost would both remain constant, and car quality is increased, the number of kilometers would also increase. In other words: the partial derivative of the demand function for kilometers with respect to car quality is positive. ${ }^{2}$

\subsection{Quality choice}

Conditional upon the choice of car quality, the indirect utility function can be written as:

$u=v(y-f(k), p(k), k)$.

Quality choice follows from the maximization of the conditional indirect utility function $v$ through the choice of $k$. We assume quality is a continuous variable that has to be chosen from a closed interval $K=\left[k^{\min }, k^{\max }\right]$. Under conventional assumptions indirect utility is continuous and must therefore reach a maximum on $K$ by Weierstrass' theorem.

We maximize $u$ in (2.5) by choice of $k$, taking into account the restrictions $k \leq k^{\max }, k \geq k^{\min }$. Assuming differentiability, the first-order conditions of this maximization problem are:

$-\frac{\partial v}{\partial(y-f)} \frac{\partial f}{\partial k}+\frac{\partial v}{\partial k}+\frac{\partial v}{\partial p} \frac{\partial p}{\partial k}+\lambda-\mu=0$

\footnotetext{
${ }^{2}$ See Appendix A.
} 
$\lambda\left(k-k^{\min }\right)=0$

$\mu\left(k^{\max }-k\right)=0$

$\lambda, \mu>0$.

In this system $\lambda$ and $\mu$ are the Lagrange multipliers associated with the two constraints. An interior solution exists when both Lagrange multipliers are equal to zero. In that case the first condition reads:

$-\frac{\partial v}{\partial(y-f)} \frac{\partial f}{\partial k}+\frac{\partial v}{\partial k}+\frac{\partial v}{\partial p} \frac{\partial p}{\partial k}=0$.

This condition requires the marginal benefit $\frac{\partial v}{\partial k}$ (the higher utility caused by the better quality) to be equal to the total marginal cost $\frac{\partial v}{\partial(y-f)} \frac{\partial f}{\partial k}-\frac{\partial v}{\partial p} \frac{\partial p}{\partial k}$ (the lower utility caused by the higher costs). Note that this condition does not require that marginal fixed cost $\partial f / \partial k$ and marginal variable costs $\partial p / \partial k$ have opposite signs. Both can be positive and we have argued in the introduction that this is likely to be the case for at least some characteristics of housing, cars and other durables. However, condition (2.7) implies that with a positive marginal utility of quality the total marginal cost must be positive, which implies that at least one of the two marginal costs (fixed or variable) must be positive. If the marginal utility of quality is equal to zero, the two marginal costs have to be of opposite sign.

In what follows, we concentrate on interior solutions, since we do not see many households choosing the lowest or highest possible car qualities. That is, we interpret the market for automobiles as a continuum of submarkets for various qualities that are all supplied and demanded. We will later return to the conditions under which this is consistent with our theoretical model.

When marginal fixed and variable costs are both positive, (2.7) implies that an interior solution is only possible if the marginal utility of quality is positive. That is, it must be the case that the consumer derives utility from that quality characteristic immediately. If this condition is not fulfilled, as is likely to be the case, for instance, for fuel efficiency, the marginal utility of the characteristic is zero, and the two marginal costs must be of opposite sign for (2.7) to hold.

Condition (2.7) can be rewritten in two alternative ways. Application of Roy's identity and rearrangement of terms leads to the first of these equivalent statements:

$w t p(k)=\frac{\partial f}{\partial k}+q \frac{\partial p}{\partial k}$

where $w t p(k)$ denotes (the absolute value of) the marginal willingness to pay for quality which is defined as: 
$w t p(k)=\frac{\partial v / \partial k}{\partial v / \partial(y-f)}$

This equation states that the marginal willingness to pay for quality - its benefits - must be equal to the sum of the implied change in fixed and total variable costs. Alternatively, we can rewrite (2.7) as:

$\frac{\partial f}{\partial k}=q\left(\operatorname{mrs}(k)-\frac{\partial p}{\partial k}\right)$,

where $m r s(k)$ denotes the marginal rate of substitution between quality and variable cost which is defined as:

$\operatorname{mrs}(k)=-\frac{\partial v / \partial k}{\partial v / \partial p}$.

The right-hand side of (2.10) is the product of the quantity of the services provided by the durable and the difference between the marginal rate of substitution between the quality of the durable and the variable costs, and the marginal variable cost of quality. The former can be interpreted as the willingness to pay for extra quality, expressed as an increase in the variable cost. The expression between parentheses in (2.10) therefore gives an excess willingness to pay for quality over the increase in variable cost. This extra willingness to pay is needed to cover the increase in fixed costs associated with the higher quality.

Equation (2.10) is our preferred specification of the first order condition and we define a new variable $D(k)$ as:

$D(k)=-\frac{\partial f}{\partial k}+q\left(\operatorname{mrs}(k)-\frac{\partial p}{\partial k}\right)$.

The necessary first order condition for an interior solution of the quality choice problem is: $D(k)=0$. The sufficient condition for an interior solution to be a maximum is that the second derivative of indirect utility with respect to $k$ is negative, or $\partial D(k) / \partial k<0$ :

$\frac{\partial D(k)}{\partial k}=-\frac{\partial^{2} f}{\partial k^{2}}+\frac{d q}{d k}\left(m r s(k)-\frac{\partial p}{\partial k}\right)+q\left(\frac{\partial m r s(k)}{\partial k}-\frac{\partial^{2} p}{\partial k^{2}}\right)$.

In this equation $d q / d k$ is the total derivative of the demand for kilometers with respect to $k$ :

$\frac{d q}{d k}=-\frac{\partial q}{\partial(y-f)} \frac{\partial f}{\partial k}+\frac{\partial q}{\partial p} \frac{\partial p}{\partial k}+\frac{\partial q}{\partial k}$.

The sign of $\partial D(k) / \partial k$ in (2.13) is indeterminate. To help determine its sign, we may assume that the functions $f$ and $p$ are both convex, and that the marginal rate of substitution between quality and variable cost is decreasing in $k$. However, this leaves us with the fundamental problem that the sign of $d q / d k$ is indeterminate. The (reasonable) assumptions made earlier determine the signs of the three partial derivatives of $q$. Assuming that the fixed cost is increasing in $k$, as seems natural, implies that the first term on the right-hand side of (2.14) is negative. The third term is nonnegative, while the sign of the second term is ambiguous. In 
order to determine the sign of $d q / d k$ in general, assumptions on preferences as well as the variable and fixed cost functions are necessary. It seems difficult to find a plausible combination of such assumptions at the level of the individual consumer.

We will therefore follow an alternative route to motivate the validity of the second order condition (2.13). We take the point of view that at the level of the market, car prices will adjust so as to ensure that every car quality in $K$ will be demanded by some consumers. That is, we posit that the market for cars functions in such a way that the fixed cost function $f$ adjusts to market circumstances to ensure that demand and supply for every quality in $K$ are equal to each other. This will be discussed in detail in the next subsection.

\subsection{Price equilibrium on the market for cars}

A market equilibrium is a function $f(k)$ for which all consumers have a $k \in K$ for which the first and second order conditions for utility maximization are satisfied and all cars that are available in the market are owned by a consumer.

We start by limiting our attention to cases in which consumer preferences and variable cost are such that

Assumption 3. The marginal rate of substitution between quality and variable cost is larger than the marginal effect of quality on variable cost: $\operatorname{mrs}(k)-\frac{\partial p}{\partial k}>0$,

is satisfied. This assumption says that consumers always prefer to drive a higher quality car if the marginal fixed costs of quality are equal to zero. Violation of this assumption implies that the first order condition (2.10) can only hold with marginal fixed cost $\frac{\partial f}{\partial k}<0$, which does not seem to be a relevant case to analyze.

Now consider a market equilibrium in which optimal car quality is increasing in income under ceteris paribus conditions. That is, if all consumer characteristics, except income, are kept constant, a higher income will imply a higher optimal car quality. Taking the total derivative of (2.12) we can write this property as:

$\frac{d k}{d y}=-\frac{\partial D(k) / \partial y}{\partial D(k) / \partial k}>0$.

The numerator of the second expression can be elaborated as:

$\frac{\partial D(k)}{\partial y}=\frac{\partial q}{\partial y}\left(\operatorname{mrs}(k)-\frac{\partial p}{\partial k}\right)+q \frac{\partial m r s}{\partial y}$. 
Since car kilometers are normal and the term between large brackets is positive by assumption 3, this expression is positive under:

Assumption 4. The marginal rate of substitution between car quality and variable cost, $\operatorname{mrs}(k)$ is nondecreasing in income $\mathrm{y}: \frac{\partial m r s(k)}{\partial y} \geq 0$.

This assumption seems plausible. Since we know, by assumption 2, that car kilometers are normal, assumptions 3 and 4 guarantee that $\partial D(k) / \partial y>0$. We have therefore shown that the second order condition $(\partial D(k) / \partial k<0)$ is automatically satisfied for a function $f(k)$ for which all consumers have a $k \in K$ for which the first order condition for utility maximization is satisfied, if this $k$ is increasing in consumer income (as indicated in 2.15).

The question that remains to be answered is whether there exists such a function $f(k)$ that also satisfies the other condition for market equilibrium, viz. that demand equals supply. Providing an answer to this question in the most general terms is outside the scope of this paper. In Appendix B we discuss the special case of a population of car-owning households with identical tastes that differ in incomes, where $k$ is a scalar and show that a solution exists under general conditions and provide an affirmative answer.

\subsection{Marginal prices and structural parameters}

To investigate the possibility of giving a structural interpretation to our estimates we now discuss a simple example. Let the indirect utility function be given as: ${ }^{3}$

$v=\left(\frac{\beta+\alpha \gamma+\beta \gamma p(k)+\gamma^{2}(y-f(k))+\delta \gamma k}{\gamma^{2}}\right) e^{-\gamma(p(k)-(\delta / \beta) k)}$

with $\alpha, \gamma, \delta>0, \beta<0$. The demand for kilometers follows by Roy's identity:

$q=\alpha+\beta p(k)+\gamma(y-f(k))+\delta k$.

The marginal rate of substitution between car quality $k$ and variable cost $p$ can be determined as:

$\operatorname{mrs}(k)=-\frac{\delta}{\beta}$,

which shows that Assumption 4 is satisfied. (2.19) shows that for indirect utility function (2.17) the marginal rate of substitution between car quality and variable cost is determined only by the structural parameters of the utility function only. ${ }^{4}$

\footnotetext{
${ }^{3}$ This is a simple variant of the indirect utility function derived by Hausman (1981) for the case of a linear demand function.
} 
There exists other indirect utility functions for which this is also the case. Such indirect utility functions satisfy a strengthened version of assumption 4 in which $\frac{\partial m r s(k)}{\partial y}=0$, which implies that indirect utility (2.5) can be written as: $u=v\left(y-f(k), v^{\prime}(p(k), k)\right)$. Moreover, the subutility function $v$ ' should be linear in its two arguments. For instance, for the indirect utility function (2.17) we have $v^{\prime}(p(k), k)=\beta p(k)+\delta k$. Apart from the linear demand function (2.18), some partial logarithmic demand functions can be derived from indirect utility functions that satisfy these requirements:

$\ln (q)=\alpha+\beta p+\gamma(y-f(k))+\delta k$,

$\ln (q)=\alpha+\beta p+\gamma \ln (y-f(k))+\delta k$.

If we can interpret the marginal rate of substitution between quality and variable cost as a parameter of the utility function, it reveals a structural aspect of consumer behavior. To see how it can be estimated, rewrite the first order condition (2.10) as:

$\operatorname{mrs}(k)=\frac{\partial p}{\partial k}+\frac{\partial f}{\partial k} / q$.

Since we estimate the two marginal costs occurring in this equation for each consumer, and observe the number of kilometers driven in the data, this allows us to compute the $m r s(k)$ at the level of the individual consumer. To do so, we have to assume that each consumer's utility function satisfies the indirect separability conditions mentioned above, but the parameters of the utility function are individual-specific. This procedure is similar to the one Bajari and Benkard (2002) used to provide a structural interpretation to their investigation of the determinants of the willingness to pay for housing characteristics. ${ }^{5}$

To summarize, in this section we have developed a model for ownership, use and quality choice of a durable and studied the conditions for an interior solution in the context of market equilibrium. The validity of the second order condition for an interior solution is difficult to guarantee at the level of the individual agent for arbitrary fixed cost functions, but is automatically implied if we restrict attention to fixed cost functions that equilibrate the market.

\footnotetext{
${ }^{4}$ Eq. (2.19) relates the $m r s$ to a ratio of coefficients of the utility function, but we can easily reparametrize in such a way that the marginal rate of substitution is a single parameter of the indirect utility function.

${ }^{5}$ The utility function used by Bajari and Benkard (2002) is not suitable for the purposes of the present paper since it is quasilinear (implying that demand for car kilometers is insensitive to income).
} 


\section{The data}

\subsection{Introduction}

We study car demand in Denmark. The data are derived from annual register data from Statistics Denmark and a car model database from the Danish car dealer association (DAF) ${ }^{6}$ for the year 2004. The combination of these two databases results in a sample sufficiently detailed to explore the concepts proposed in this paper.

We have information from the car model database on car attributes of all new model variants supplied at the car market in Denmark in 2004 including the catalogue price of a new car, depreciation rate, car brand/model/type, vehicle cabin type (sedan, hatch, MPV, station car, and other), engine horsepower, and indicator for car transmission system. Other information on car attributes and household characteristics is derived from annual register data from Statistics Denmark, i.e. car tare, car total allowed weight incl. passengers and cargo, fuel efficiency, car vintage, and information on car owner's socio-economic characteristics (e.g. age, gender, income, etc.). Cabin capacity is most likely an important characteristic of a car. Since we do not observe cabin capacity measured in cubic meters, car capacity has been calculated as the difference between total allowed vehicle weight incl. passengers and cargo and the vehicle tare. Since the car model database includes more than thousand car brand/model/make combinations, we focus only on the most frequently purchased brand variants: Toyota, Suzuki, Hyundai, Peugeot, Fiat, Kia, Skoda, Mazda, Daewoo, Renault, Nissan, Volvo, Audi, Mitsubishi, other eastern car brands (Honda, Daihatsu, Subaru and others), and other car brands (Chrysler, Jeep, Land-Rover, Smart, Alfa Romeo, Mercedes-Benz, BMW, Seat, and others).

Our register data includes information about the so-called MOT tests. These are compulsory tests that take place before a car is sold, when it is four years old, and from then on every second year. ${ }^{7}$ Annual number of driven kilometers has been calculated using information on exact odometer readings from the MOT tests. We use the odometer reading of the second MOT test (i.e. the first one after the car was sold) for the cars sold in 2004 that had not switched owner after being first sold. The times when the car was bought and when it

\footnotetext{
${ }^{6}$ Danmarks Automobilforhandler Forening (DAF).

${ }^{7}$ The MOT test is a vehicle check that is compulsory for all vehicles registered in Denmark. The name derives from the Ministry of Transport. All Danish vehicles have to pass such MOT tests when first registered, and then at statutory time intervals. New automobiles owned by private persons (households) have to be approved by a second MOT test at least four years after being first registered, and then every second year. Each time a vehicle passes the MOT test, the inspection authority reads the odometer on the day of the MOT test, records date of the MOT test and several different identification data regarding the vehicle, such as vehicle id number, engine size, etc.
} 
passed its first MOT tests were both registered in months, which allows us to make a fairly accurate estimate of the annual number of kilometers driven during this time interval.

Annual fixed costs include annual depreciation, vehicle excise duty and insurance premium. The annual depreciation has been calculated, for example, for the first year of car use, by subtracting the provided average price for a one year old used car from the catalogue price. $^{8}$ The vehicle excise duty in Denmark is based on the vehicle fuel efficiency. Consequently, the vehicle excise duty has been calculated by using provided information on the vehicle fuel efficiency and the predefined statutory annual tax rates. ${ }^{9}$ The estimates of the average annual insurance premium for ten car groups are provided by bilpriser.dk and FDM (2009). Variable costs have been calculated using information on fuel consumption and expenditures associated with car maintenance. Specifically, the fuel expenditure is compiled by dividing fuel price with specific car fuel efficiency in order to get a figure for fuel costs per kilometer. The estimates of average annual maintenance expenditures for ten car groups are provided by bilpriser.dk and FDM (2009). The units of all monetary amounts are in 2004 DKK. ${ }^{10}$

\subsection{Selection of sample and descriptive statistics}

We observe the full population of registered cars in Denmark. We select cars with petrol engines $(77.8 \%$ of all cars) that were first registered in 2004 (87,798 cars). Records with missing information $(8,469$ observations) and households who sold the car between first registration and the second (MOT) test (38,792 observations) were excluded. Thus, our focus is on cases referring to new cars with petrol engines (we ignore imported second hand cars), purchased by households who did not sell the car between first registration and the first MOT test after being sold. We select households who did not sell the car between first registration and the second (MOT) test because we need annual kilometers driven for the computation of our willingness to pay and marginal rate of substitution measures. This left us with a sample of 40,537 observations. To ease the computational burden of estimating the flexible hedonic specifications, we drew a random sample of 10,000 observations.

\footnotetext{
8 The car model database includes information on expected prices for one year old cars for all brand/model/makes combinations calculated for the car associated with 20,000 driven kilometres. Moreover, the database provides brand/model/make specific price correction factors for deviation from the expected average annual kilometre driven. Thus, the expected depreciation has been corrected for the car wear. The depreciation includes also costs of delivery and all relevant financial expenditures (e.g. interests).

${ }^{9}$ The annual tax rates associated with the vehicle excise duty can be found in DAF (2005).

${ }^{10}$ One DKK is approximately $0.13 €$.
} 
Table 1. Summary statistics

\begin{tabular}{|c|c|c|c|c|}
\hline Variable & Mean & Std. Dev. & Minimum & Maximum \\
\hline Fixed annual costs (DKK) & 32,468 & 12,449 & 15,019 & 118,138 \\
\hline Variable costs (DKK/km) & 2.1122 & 0.2521 & 1.6293 & 3.0537 \\
\hline Number of driven kilometers $(\mathrm{km})$ & 15,927 & 7,618 & 251 & 72,440 \\
\hline Car capacity (kg) & 521 & 63 & 250 & 875 \\
\hline Engine horsepower & 98.50 & 29.02 & 50.00 & 395.00 \\
\hline Automatic transmission (share) & 0.0422 & 0.2011 & 0.0000 & 1.0000 \\
\hline
\end{tabular}

Notes: Number of observations is 10,000 .

Table 1 shows a summary of the main variables. They show that the mean annual fixed costs and mean annual expenditure associated with car variable costs are of more or less the same magnitude. The mean annual fixed costs are 32,468 DKK. The mean annual number of driven kilometers by one car is 15,927 kilometers, and the mean variable costs are 2.11 DKK per kilometer. The mean annual total expenditure associated with the variable costs of ownership and use of a car is then 33,641 DKK, about $3.6 \%$ higher than the mean fixed annual costs. The mean car capacity and the mean engine horsepower are $521 \mathrm{~kg}$ and $99 \mathrm{hp}$, respectively. The share of cars with automatic transmission is approximately $4.2 \%$.

Table 2. Regression of natural logarithm of fixed cost on natural logarithm of variable cost

\begin{tabular}{|c|c|c|c|}
\hline & [1] & [2] & [3] \\
\hline Natural logarithm of variable cost & $\begin{array}{l}2.4868^{* * *} \\
(0.0087)\end{array}$ & $\begin{array}{l}1.5311^{* * *} \\
(0.0107)\end{array}$ & $\begin{array}{l}1.5001 * * * \\
(0.0193)\end{array}$ \\
\hline Natural logarithm of car capacity & & $\begin{array}{l}0.2713^{* * *} \\
(0.0095)\end{array}$ & $\begin{array}{l}0.1341 * * * \\
(0.0082)\end{array}$ \\
\hline Natural logarithm of engine horsepower & & $\begin{array}{l}0.4569 * * * \\
(0.0046)\end{array}$ & $\begin{array}{l}0.3942 * * * \\
(0.0052)\end{array}$ \\
\hline Dummy indicating automatic transmission & & $\begin{array}{l}0.0733^{* * *} \\
(0.0042)\end{array}$ & $\begin{array}{l}0.0399 * * * \\
(0.0033)\end{array}$ \\
\hline Dummies indicating car brands & No & No & Yes \\
\hline Dummies indicating type of car cabin & No & No & Yes \\
\hline Intercept & $\begin{array}{l}8.4790 * * * \\
(0.0065)\end{array}$ & $\begin{array}{l}5.3342^{* * *} \\
(0.0503)\end{array}$ & $\begin{array}{l}6.5675^{* * *} \\
(0.0455)\end{array}$ \\
\hline R-squared & 0.7163 & 0.8140 & 0.9009 \\
\hline No. observations & 40,537 & 40,537 & 40,537 \\
\hline
\end{tabular}

The correlation between variable and annual fixed costs equals $0.80,{ }^{11}$ which suggests that there does not exist a trade-off between both types of costs in the data. We have elaborated this issue by carrying out some regressions. Results are reported in Table 2. A basic regression of the fixed cost on the variable cost (column [1]) yields a positive and significant coefficient for the variable cost, while explaining almost two thirds of the variation in the fixed cost. Adding controls for the car capacity, the engine horsepower and

${ }^{11}$ Pearson correlation; the correlation is significant at the 0.01 level. 
the automatic transmission (column [2]) decreases the coefficient for the variable cost, but it remains positive and highly significant. When dummies for the car brands and the cabin make are added the coefficient for the variable cost is again smaller, but still positive and significant at the $1 \%$ level (column [3]). Thus, a model focusing on the trade-off between fixed and variable costs would ignore much of the variation present in the data.

\section{Empirical strategy and results: the marginal willingness to pay for car attributes}

Rosen (1974) pioneered the analysis of hedonic markets in a perfectly competitive setting and showed that the first derivative of the hedonic price function with respect to the individual attribute equals the marginal willingness to pay for this attribute. We will not provide a review of the subsequent literature that builds on his insights. Perhaps the most influential study referring to the car market is Berry et al. (1995) who study the market for new cars. They include fuel efficiency as one of the car characteristics in their model and focus on the price of new cars. The model we developed above suggests that the marginal fixed cost for quality characteristics is the difference between the marginal willingness to pay for that characteristic and the marginal variable cost. The conventional approach ignores the latter term and equates marginal willingness to pay with marginal fixed cost. This implies, for instance, that the willingness to pay for quality characteristics in terms of a higher price for new cars is independent of the fuel price, whereas our approach suggests that that consumer's willingness to pay for quality characteristics of new cars varies inversely with the fuel price. Below, we estimate the full marginal willingness to pay for a car attribute as the change in the total annual costs of ownership and use of a durable that results from a small change in that attribute. We showed in section 2 that in our model it is proportional to the first derivative of the hedonic price (= fixed cost) function only if the variable cost of the durable is not affected by that attribute. If the variable cost is affected, there is a second term that is proportional to the hedonic variable cost function. ${ }^{12}$ Application of our model therefore requires estimation of the hedonic price functions for both the variable and the fixed costs.

Our empirical analysis focuses on four basic car attributes that are able to explain much of the variance in both the fixed costs and the variable costs: engine horsepower, car capacity, type of the transmission system and the type of car cabin. Other, more subjective attributes, such as prestige of ownership, may affect both the fixed costs and the variable

\footnotetext{
${ }^{12}$ For example, car cabin capacity affects automobile fuel efficiency (fuel consumption per kilometre) and thus variable costs.
} 
costs. We include the car brands in the empirical analysis as proxies for these difficult-toquantify attributes.

\subsection{Hedonic fixed and variable cost functions}

Hedonic price functions for cars have been estimated ever since hedonic regressions have been run (see among others Court, 1939, and Grilliches, 1961). The recent literature stresses the importance of using flexible methods to estimate the hedonic functions (see e.g. Pace, 1995 and Anglin and Gençay, 1996). We follow Bajari and Kahn (2005) who use local linear regression to recover willingness to pay for housing attributes. Local linear methods have the same asymptotic variance and a lower asymptotic bias than the Nadaraya-Watson estimator, and the same asymptotic bias and a lower asymptotic variance than Gasser-Mueller estimator (Fan and Gijbels, 1996).

We assume that the fixed and variable costs of each car type $j=1 \ldots J$, satisfy:

$\log f\left(k_{j}\right)=\log F\left(k_{j}\right)+\xi_{j}^{f}$

$\log p\left(k_{j}\right)=\log P\left(k_{j}\right)+\xi_{j}^{p}$

where $F$ and $P$ are unknown hedonic price functions, $k_{j}$ is a vector of car characteristics and the $\xi$ s denote characteristics observed by the consumer but not by the researcher. The vector $k$ of car characteristics consists of: $h p$, the engine horsepower; $c$, the car capacity; aut, a dichotomous variable that equals 1 if car's transmission system is automatic and 0 otherwise; cabin, a set of dummy variables indicating type of the car cabin; brand, a set of dummy variables indicating the car brands. Our local linear approach approximates the function $F$ and $P$ locally for each observed car as:

$$
\begin{gathered}
\log F_{j}(k)=\alpha_{0, j}^{f}+\alpha_{1, j}^{f} \log (h p)+\alpha_{2, j}^{f} \log (c)+\alpha_{3, j}^{f} \text { aut }+ \\
\sum_{s=4}^{7} \alpha_{s, j}^{f} \operatorname{cabin}_{s}+\sum_{r=8}^{22} \alpha_{r, j}^{f} \text { brand }_{r}+\xi_{j}^{f}, \\
\log P_{j}(k)=\alpha_{0, j}^{p}+\alpha_{1, j}^{p} \log (h p)+\alpha_{2, j}^{p} \log (c)+\alpha_{3, j}^{p} \text { aut }+ \\
\sum_{s=4}^{7} \alpha_{s, j}^{p} \operatorname{cabin}_{s}+\sum_{r=8}^{22} \alpha_{r, j}^{p} \text { brand }_{r}+\xi_{j}^{p} .
\end{gathered}
$$

We use local linear regression to approach the hedonic price functions at each observation point $j .{ }^{13}$ In particular, we use weighted least squares to estimate the hedonic coefficients $\alpha_{j}=\left[\alpha_{0, j} \ldots \alpha_{22, j}\right]^{\prime}$. That is, for each:

$\alpha_{j}=\arg \min (\boldsymbol{r}-\boldsymbol{K} \boldsymbol{\alpha})^{\prime} \boldsymbol{W}_{\boldsymbol{j}}(\boldsymbol{r}-\boldsymbol{K} \boldsymbol{\alpha})$

\footnotetext{
${ }^{13}$ For description and discussion of local polynomial methods see e.g. Fan and Gijbels (1996) and Härdle (1993).
} 
where $\boldsymbol{r}$ is the $J \times 1$ vector of fixed or variable costs for all cars $j\left(\boldsymbol{r}=\boldsymbol{f}=\left[f_{j}\right]\right.$ or $\boldsymbol{r}=\boldsymbol{p}=$ $\left[p_{j}\right]$ ), $K$ is a $J \times 23$ matrix of regressors (which for each product $j$ includes an intercept and 22 attributes), and $\boldsymbol{W}_{\boldsymbol{j}}$ is a $J \times J$ diagonal matrix of kernel weights. The kernel weights are a function of the distance between the characteristics of the car $j^{\prime}$ and car $j$. So, the local regression assigns greater importance to observations with attributes close to $j .{ }^{14}$ We use normal kernel function

$W(z)=\prod_{m=1}^{22} N\left(\frac{z_{m}}{\widehat{\sigma}_{m}^{2}}\right)$

$W_{h}(z)=W\left(\frac{z}{h}\right) / h$.

In these equations $N$ is the standard normal density function and $h$ is the bandwidth. We evaluate the normal distribution for the $m$-th car characteristic at $z_{m} / \hat{\sigma}_{m}^{2}$, where $\hat{\sigma}_{m}^{2}$ is the sample standard deviation of attribute $m$. The choice of kernel bandwidth is central to the local regression (Altman, 1992) and the literature describes appropriate methods for choosing the bandwidth (see e.g. Fan and Gijbels, 1996, and Härdle, 1993) to approximate the hedonic price function. In the present study we focus on the first derivatives of the hedonic function and then a larger bandwidth is recommended in the literature (see, for instance, McMillen, 2010). Based on visual inspection of the estimates, we choose the bandwidth $(h)$ equal to 4. Moreover, the estimates of (4.5) allow us to recover estimates of the unobservable car characteristic associated with the fixed costs $\left(\xi_{j}^{f}\right)$ and the variable cost $\left(\xi_{j}^{p}\right)$ from (4.1) and (4.2). This unobservable car characteristic can be estimated as the residuals to the hedonic regression functions, i.e. $\xi_{j}^{f}=\log f\left(k_{j}\right)-\log F\left(k_{j}\right)$ and $\xi_{j}^{p}=\log p\left(k_{j}\right)-\log P\left(k_{j}\right)$. We use the standard hedonic assumption that the unobserved car characteristics are independent of the observed car characteristics. ${ }^{15}$

\subsection{Estimation results}

This section presents estimates of the hedonic price functions for the variable and the fixed cost functions (4.1) and (4.2). Estimated versions of the fixed and variable cost functions enable us to compute local (individual-specific) estimates of the marginal fixed costs and the marginal variable cost implied of the specific car attribute. As we noted above, estimation of marginal fixed costs is conventional in the hedonic price literature, whereas estimation of the

\footnotetext{
${ }^{14}$ Since we assume that data point that are close together have means that are more similar than data points that are far apart, it makes sense to use a weighted average, with smaller weight for data points farther from the centre of bandwidth.

${ }^{15}$ For discussion of the implication of this assumption for the car market equilibrium, see Berry et al. (1995).
} 
marginal variable cost is much less common. We can also compute the (full) marginal willingness to pay for a car attribute from (2.8) using obtained estimates of the implicit prices faced by the household $i$ from (4.1) and (4.2) together with information about the number of kilometers driven by the household.

For both the fixed cost and the variable cost functions the estimated implicit prices of the car attributes have intuitively plausible signs and magnitudes in almost all cases. Then for each car $j$ we compute the marginal fixed costs of attribute $m\left(m f c_{j, m}=\partial F_{j} / \partial k_{m}\right)$, and the marginal variable costs of that attribute $\left(m v c_{j, m}=\partial P_{j} / \partial k_{m}\right)$. Moreover, using information about the number of kilometers driven, we compute on the basis on (2.8) the total marginal willingness to pay of attribute $m\left(w t p_{j, m}\right)$. These estimates are household-specific in the sense that a unique set of the marginal fixed costs, the marginal variable costs and the total marginal willingness to pay are estimated for each value of $j=1, \ldots, J$.

Figure 2 presents histograms and estimated kernel distributions of the marginal willingness to pay, the marginal variable costs, and the marginal fixed costs for the engine horsepower and for the car capacity for the 10,000 Danish car owners. This figure shows that the marginal willingness to pay is not symmetrically distributed, but skewed to the right. Moreover, the distribution of the full marginal willingness to pay is smoother than that of either the marginal fixed cost or the marginal variable cost as would be expected if a heterogeneous population of consumers whose tastes can be described by a smooth distribution function sorts over a large number of car makes by taking into account full marginal costs. It is also clear from these figures (in particular from a comparison of the distributions of marginal willingness to pay and the marginal fixed costs) that the marginal variable cost contributes substantially to our measurement of the total marginal willingness to pay. An average car's share of the marginal fixed costs of the total marginal willingness to pay is approximately $79 \%{ }^{16}$ implying that one fifth of the full marginal cost refers to variable cost.

\footnotetext{
${ }^{16}$ The average car in this context is a Toyota sedan with manual transmission system, 99 horsepower, and the capacity of 521 kilograms. For summary statistics for the computed willingness to pay measures, see Appendix A, Table A.1.
} 
Figure 2a. Histogram and estimated kernel distribution of the marginal willingness to pay, the marginal fixed costs, and the marginal variable costs for engine horsepower (DKK)

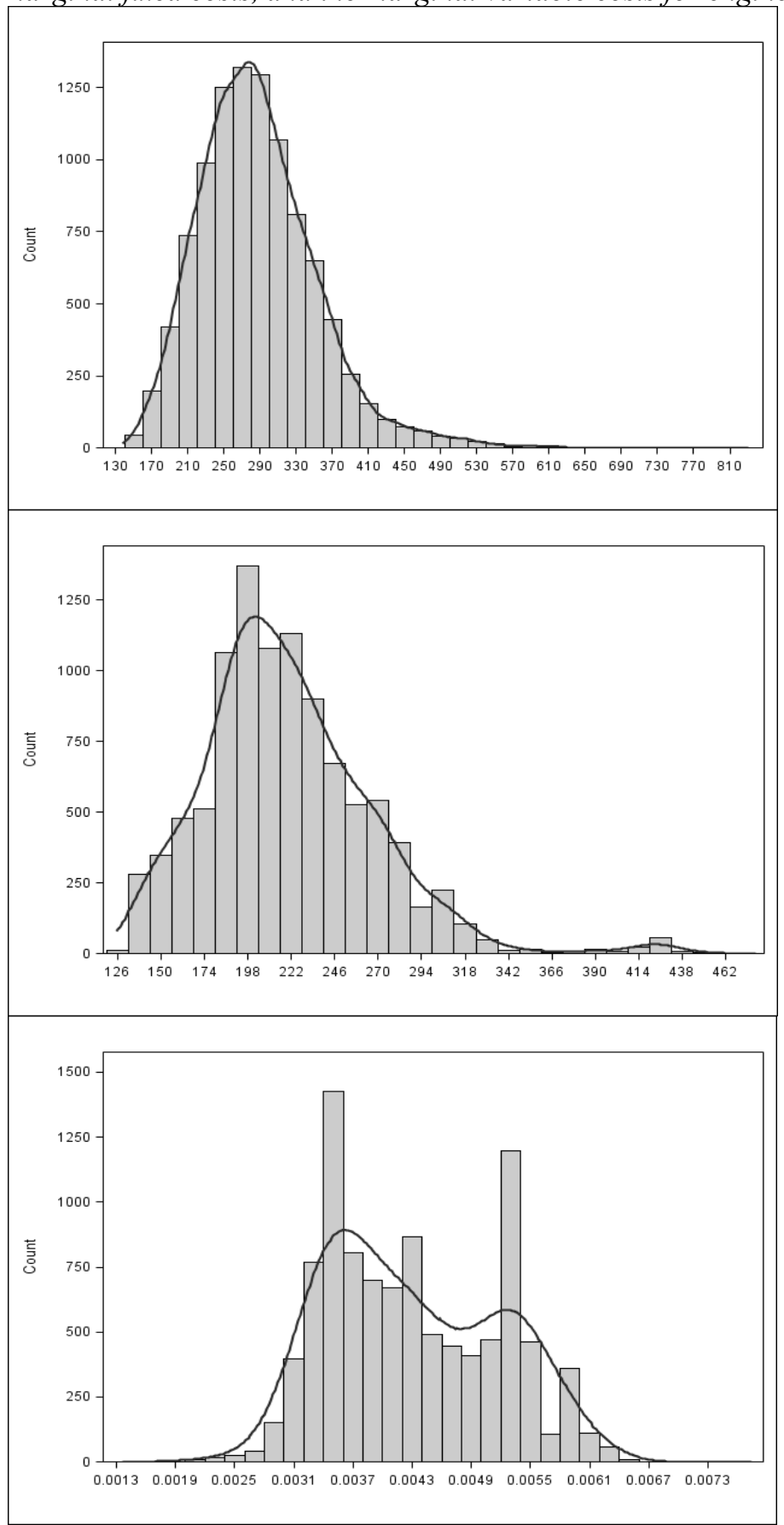

(a) $w t p$

(b) $m f c$

(c) mvc

Notes: The Kernel density estimation is performed here using SAS KDE procedure (SAS Institute Inc., 2009). 
Figure $2 \mathrm{~b}$. Histogram and estimated kernel distribution of the marginal willingness to pay, marginal fixed costs, and marginal variable costs for car capacity (DKK)

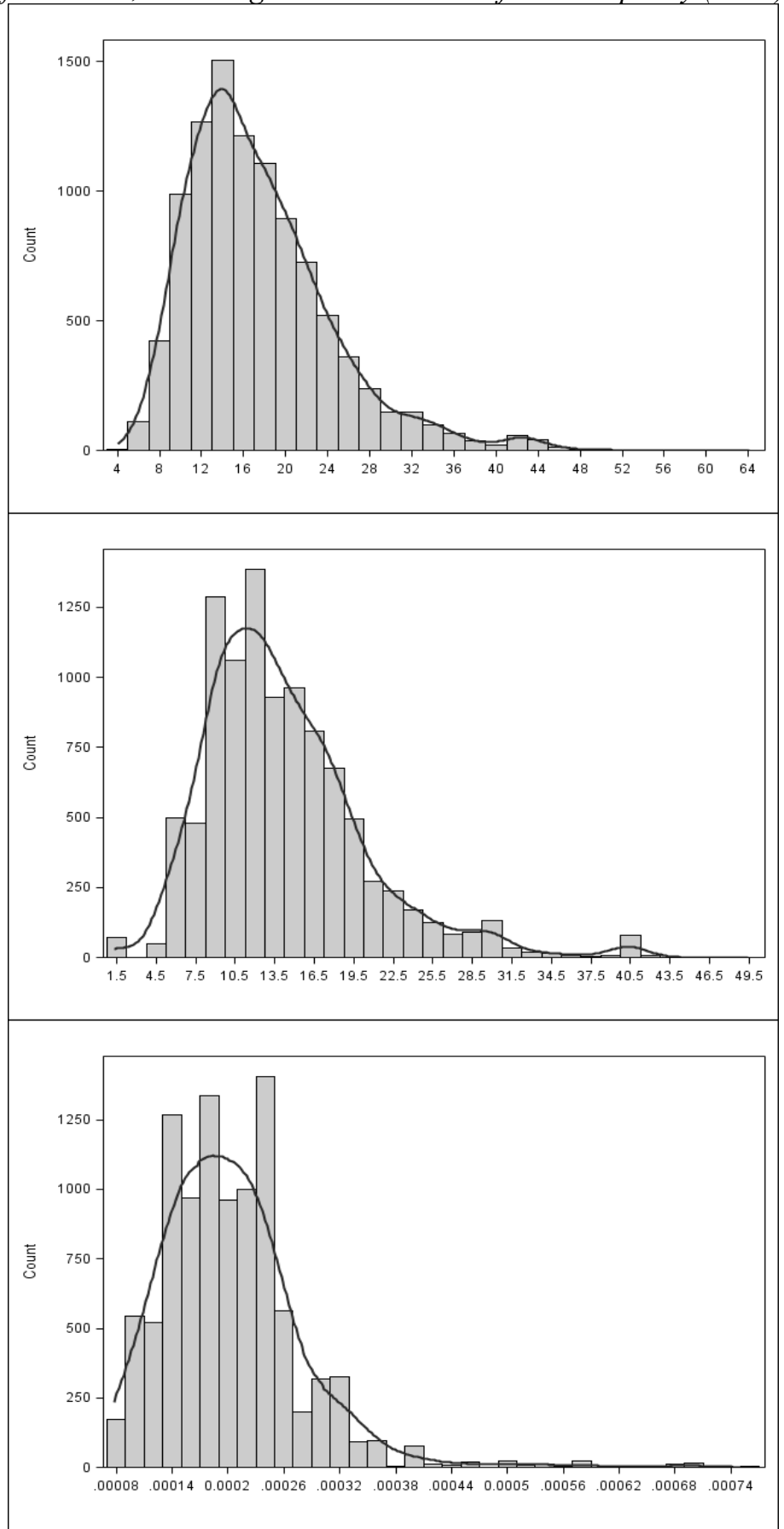

(a) wtp

(b) $m f_{c}$

(c) mvc

Notes: The Kernel density estimation is performed here using SAS KDE procedure (SAS Institute Inc., 2009).

Both the marginal fixed costs and the marginal variable costs are positively correlated with the number of kilometers driven, i.e. 0.36 and 0.19, respectively (see Appendix C, Table C.2). Thus, households with a relatively high demand for driving, demand more expensive 
cars. ${ }^{17}$ This is consistent with our model even in the simplified case in which the marginal rate of substitution between quality and variable cost is a constant: a larger number of kilometers driven still increases the willingness to pay for quality in this situation (see $(2.10))$.

Table 3 shows that Danish households are on average willing to pay 287 DKK per year for an additional engine horsepower and 17 DKK per year for an additional kilogram of car capacity. Moreover, the total marginal willingness to pay for these two car attributes are dominated by the associated marginal fixed costs, i.e. $220 \mathrm{DKK}$ and $14 \mathrm{DKK}$ for engine horsepower and car capacity, respectively. The total marginal willingness to pay for the car automatic transmission system, compared to the car manual transmission system, is 4,529 DKK. The marginal fixed costs for this car attribute amount to approximately half of the total marginal willingness to pay of the car attribute. MPVs, station cars and other car cabin (including SUVs) have higher total marginal willingness to pay and only sedans have lower total marginal willingness to pay compared to hatchbacks. Unsurprisingly, car brands associated with high quality and prestige (e.g. Audi) have on average a higher total marginal willingness to pay than economical car brands (e.g. Hyundai).

Table 3. Means and standard deviations (DKK)

\begin{tabular}{|c|c|c|c|c|c|c|}
\hline & \multicolumn{2}{|c|}{ WTP } & \multicolumn{2}{|c|}{ MFC } & \multicolumn{2}{|c|}{ MVC } \\
\hline & Mean & s.d. & Mean & s.d. & Mean & s.d. \\
\hline Horse power & 287 & 66.16 & 220 & 46.77 & 0.0043 & 0.0009 \\
\hline Capacity (kg) & 17.44 & 6.91 & 14.25 & 6.18 & 0.0002 & 0.0001 \\
\hline Automatic transmission & 4,529 & 1,994 & 2,065 & 1,057 & 0.1500 & 0.0170 \\
\hline MPV & 11,207 & 4,103 & 6,123 & 2,115 & 0.3200 & 0.3400 \\
\hline Sedan & $-4,480$ & 1,822 & $-2,218$ & 985 & -0.1400 & 0.0180 \\
\hline Station car & 11,110 & 4,171 & 6,847 & 2,694 & 0.2700 & 0.0290 \\
\hline Other cabin & 12,054 & 4,531 & 6,647 & 2,435 & 0.3400 & 0.0390 \\
\hline Suzuki & $-7,302$ & 2,748 & $-6,101$ & 2,548 & -0.0750 & 0.0140 \\
\hline Hyundai & $-8,071$ & 2,856 & $-7,308$ & 2,817 & -0.0490 & 0.0130 \\
\hline Peugeot & -439 & 1,036 & -887 & 1,066 & 0.0270 & 0.0150 \\
\hline Fiat & $-8,839$ & 2,288 & $-5,418$ & 2,193 & -0.0220 & 0.0240 \\
\hline Kia & $-6,352$ & 2,253 & $-5,472$ & 2,172 & -0.0560 & 0.0180 \\
\hline Skoda & $-7,299$ & 2,682 & $-4,480$ & 1,929 & -0.1800 & 0.0220 \\
\hline Mazda & 1,008 & 901 & 980 & 946 & 0.0010 & 0.0120 \\
\hline Daewoo & $-5,753$ & 2,249 & $-6,055$ & 2,432 & 0.0180 & 0.0140 \\
\hline Renault & $-2,384$ & 1,153 & $-1,764$ & 1,100 & -0.0390 & 0.0130 \\
\hline Nissan & 581 & 1,106 & 324 & 1,049 & 0.0150 & 0.0160 \\
\hline Volvo & 1,912 & 1,464 & 1,852 & 1,336 & 0.0024 & 0.0170 \\
\hline Audi & 13,439 & 5,415 & 13,090 & 5,159 & 0.0200 & 0.0170 \\
\hline Mitsubishi & $-5,010$ & 1,575 & $-5,028$ & 1,690 & 0.0001 & 0.0100 \\
\hline Other eastern car brands & -191 & 746 & 698 & 746 & -0.0560 & 0.0110 \\
\hline Other car brands & 1,049 & 1,159 & 1,241 & 1,127 & -0.0110 & 0.0140 \\
\hline
\end{tabular}

Notes: Wtp, mfc, and mvc are computed using the estimated coefficients from the hedonic price equations. The number of observations is 10,000 .

\footnotetext{
${ }^{17}$ For the histogram and the estimated kernel distribution of the number of kilometres driven, see the Appendix C, Figure C.1.
} 


\section{Further investigation of preferences}

The relationship between the marginal willingness to pay for the quality attributes and the structural parameters of the utility function (taste parameters) is of great interest. Bajari and Benkard (2002) have proposed a methodology for linking the marginal willingness to pay for the quality attributes to the (structural) parameters of individual specific utility functions. However, if only one choice per households is observed, as is the case in our data, severe restrictions have to be imposed on the utility function in order to recover household specific taste parameters, i.e. a log-linear specification for consumer preferences have to be assumed (Bajari and Benkard, 2002). The utility function assumed by Bajari and Benkard implies demand functions that do not depend on income and have price elasticity that equals -1 , which is unattractive for the purposes of the present study. However, we showed in section 2 above that it is possible to relate the implicit prices for quality attribute $k$ that follows from our estimates of the fixed and variable cost functions to the marginal rate of substitution between $k$ and the variable cost $(\operatorname{mrs}(k))$ and that this variable can be considered as a structural preference parameter if one is willing to impose the necessary functional form assumptions. Under these conditions, a structural investigation of consumer tastes can be performed on the basis of estimates of the individual marginal rates of substitution.

Our estimate of the mrs follows from (2.21), which we repeat here as:

$\operatorname{mrs}\left(k_{m}\right)=\frac{\partial p(k)}{\partial k_{m}}+\frac{\partial f(k)}{\partial k_{m}} \frac{1}{q}$.

The suffix $m$ refers to the $m$-th quality attribute we consider in our empirical work, while $k$ now denotes the vector of all car attributes considered. Since we have individual-specific estimates of the marginal fixed and variable costs and information about the number of kilometers driven, we are able to construct an individual specific estimate of the marginal rate of substitution $\widehat{m r} s_{i, m}$, where the index $i$ refers to a household. An estimator of $m r s_{j, m}$ can be recovered from (4.1) and (4.2) as follows:

$\widehat{m r} s_{i, m}=\frac{\widehat{\alpha}_{j, m}^{p} p_{j}}{k_{j, m}}+\frac{\widehat{\alpha}_{j, m}^{f} f_{j}}{k_{j, m}} \frac{1}{q_{j}}$

Through (5.2) we recover household i's $\widehat{m r} s_{i, m}$ for characteristic $m$ using available data and the estimate of the (local) implicit prices recovered from the hedonic price functions. Moreover, the marginal rate of substitution between car attribute $m$ and variable cost $p$ was shown in (2.19) to be equal to the negative of the ratio of two structural parameters of specific utility function. So, we are able to recover the ratio of two structural parameters of the utility function that is equal to the marginal rate of substitution. 
After recovering household-level marginal rate of substitution between car attribute $m$ and variable cost $p$, we can relate them to the household's socio economic characteristics $d_{i}$. We assume:

$m r s_{i, m}=g_{m}\left(d_{i}\right)+\eta_{i, m}$

$E\left(\eta_{i, m} \mid d_{i}\right)=0$.

The $m r s_{i, m}$ 's are modeled as functions, $g_{m}$, of household's socio economic characteristics, $\mathrm{d}_{\mathrm{i}}$, and an orthogonal household specific residual, $\eta_{\mathrm{i}, \mathrm{m}}$. We could easily do this estimation using flexible local linear methods. However, for presentation purposes, it is more convenient to model the joint distribution of $m r s$ and demographic characteristics using a linear model. For continuous characteristics, we therefore simply estimate the following equation using robust regression ${ }^{18}$

$\widehat{m r} s_{i, m}=\theta_{0, m}+\sum_{a} \theta_{a, m} d_{i, a}+\eta_{i, m}$

Given estimates $\theta_{a, m}$, the residuals $\left(\eta_{i, m}\right)$ can be interpreted as household-specific taste shocks. Note that no parametric restrictions are imposed on the $\eta_{i, m}$.

For car attributes that take on the dichotomous values of 0 and 1 , there is no firstorder condition for utility maximization. Following Bajari and Kahn (2005) we apply a simple threshold decision making rule to estimate the $\widehat{m r} s_{i, m}$ for dichotomous attributes. Denote the value of the dichotomous car attribute as $k_{m}$. Utility maximization implies that

$\left[k_{m}=1\right] \Rightarrow\left[m r s_{i, m}>\frac{\Delta p}{\Delta k_{m}}+\frac{\Delta f}{\Delta k_{m}} \frac{1}{q}\right]$

$\left[k_{m}=0\right] \Rightarrow\left[m r s_{i, m}<\frac{\Delta p}{\Delta k_{m}}+\frac{\Delta f}{\Delta k_{m}} \frac{1}{q}\right]$

In these equations, the ratios of differences denote the changes in variable and fixed costs associated with a switch of $k_{m}$ from 0 to 1 . That is, if household $i$ chooses $k_{m}=1$, then we can infer that $i$ 's $\operatorname{mrs}_{i, m}$ exceeds the implicit cost per kilometer for this attribute.

(5.6) and (5.7) show that the mrs for dichotomous characteristics is not identified. We can only infer that the preferences for a particular household are above or below the threshold value equal to the implicit cost per kilometer of the discrete characteristic. Following Bajari and Kahn (2005) we use a logit model to explain the choice of $k_{m} \cdot{ }^{19}$ Like these authors we

\footnotetext{
${ }^{18}$ The main purpose of robust regression is to detect outliers and provide stable results in the presence of outliers. In order to achieve this stability, robust regression limits the influence of outliers. We are considering problems with outliers in the response direction. M estimation method, introduced by Huber (1973), has been applied for outlier detection and robust regression (SAS Institute Inc., 2009).

${ }^{19}$ These authors use a probit model which gives similar results in the case of dichotomous choice.
} 
normalize the coefficient on the implicit cost to -1 (see Bajari and Kahn, 2005). ${ }^{20}$ For cabin types, we follow a similar approach and estimate a multinomial logit model.

Table 4. Robust regressions of the marginal rate of substitution between quality attribute and variable cost on socio economic characteristics for continuous car attributes

\begin{tabular}{|c|c|c|}
\hline & $\begin{array}{l}{[1]} \\
\text { Engine } \\
\text { horsepower }\end{array}$ & $\begin{array}{l}{[2]} \\
\text { Car } \\
\text { Capacity }\end{array}$ \\
\hline Age & $\begin{array}{l}0.00016^{* * *} \\
(0.00001)\end{array}$ & $\begin{array}{l}0.00001^{* * *} \\
(0.00001)\end{array}$ \\
\hline Dummy indicating male & $\begin{array}{l}0.00212 * * * \\
(0.00014)\end{array}$ & $\begin{array}{l}0.00005^{* * *} \\
(0.00001)\end{array}$ \\
\hline Dummy indicating presence of children & $\begin{array}{l}0.00084 * * * \\
(0.00017)\end{array}$ & $\begin{array}{l}0.00003^{* * *} \\
(0.00001)\end{array}$ \\
\hline Dummy indicating population density $1-1,000$ & $\begin{array}{l}0.00177^{* * *} \\
(0.00019)\end{array}$ & $\begin{array}{l}0.00016^{* * * *} \\
(0.00001)\end{array}$ \\
\hline Dummy indicating population density $1,000-10,000$ & $\begin{array}{l}0.00062 * * * \\
(0.00020)\end{array}$ & $\begin{array}{l}0.00006^{* * *} \\
(0.00002)\end{array}$ \\
\hline Dummy indicating population density $10,000-100,000$ & $\begin{array}{l}0.00041^{* *} \\
(0.00021)\end{array}$ & $\begin{array}{l}0.00006 * * \\
(0.00002)\end{array}$ \\
\hline Constant & $\begin{array}{l}0.00890 * * * \\
(0.00030)\end{array}$ & $\begin{array}{l}0.00050 * * * \\
(0.00001)\end{array}$ \\
\hline $\begin{array}{l}\text { R-square } \\
\text { No. observations }\end{array}$ & $\begin{array}{l}0.0745 \\
10,000\end{array}$ & $\begin{array}{l}0.0645 \\
10,000\end{array}$ \\
\hline \multicolumn{3}{|c|}{$\begin{array}{l}\text { Notes: (1) Dependent variables are the marginal rate of substitution between continuous quality attribute and variable cost. M estimation } \\
\text { method, introduced by Huber (1973), has been applied for outlier detection and robust regression (SAS Institute Inc., 2009). Omitted } \\
\text { variable associated with dummies representing population density is the Copenhagen area with the highest population density in Denmark. } \\
* * *, * *, * \text { indicate that estimates are significantly different from zero at the } 0.01 \text {, at the } 0.05 \text { and the } 0.10 \text { level, respectively. Standard errors } \\
\text { are in parentheses. }\end{array}$} \\
\hline
\end{tabular}

The econometric results of two separate robust regressions where dependent variables are based on continuous quality attributes (i.e. engine horsepower and car capacity) are shown in table 4 . In each regression we control for the age of the car owner, dummy variables for whether the car owner is male, dummy variable indicating presence of children in the household, and dummy variables indicating the population density of the car owner's municipality. We find that the older car owners have higher $m r s$ for car capacity and engine horsepower. For every year, the car owner's willingness to accept an increase in total annual variable costs rises by about $0.03 \mathrm{DKK}$ for an additional $\mathrm{kg}$ of car capacity and 2.59 DKK for one additional engine horsepower. ${ }^{21}$ Males are willing to accept increase in total annual variable costs of about $0.80 \mathrm{DKK}$ and 33.77 DKK for a car with additional one kilogram of capacity and engine with one more horsepower. Households with children have slightly lower willingness to accept an increase in total annual variable costs for car capacity and engine horsepower, 0.48 DKK and 13.38 DKK, respectively. Finally, car owner's mrs associated

\footnotetext{
${ }^{20}$ An alternative approach, which does not require assuming that tastes lie in a parametric family, is to use the bounds approach described by Bajari and Benkard (2002).

${ }^{21}$ The willingness to accept an increase in total annual variable costs has been calculated at the average number of kilometres driven $(15,972)$ for a $1 \%$ increase in mean car capacity $(521 \mathrm{~kg})$ and mean number of engine horsepower $(98.50 \mathrm{hp})$, i.e. $5.21 \mathrm{~kg}$ and $0.99 \mathrm{hp}$.
} 
with car capacity and engine horsepower decreases with population density. Compared to the car owners with residence in Copenhagen, car owners with residence in urban areas (with population density between 1,000 and 10,000 inhabitants) are willing to accept an additional increase in total annual variable costs of about $0.49 \mathrm{DKK}$ for an additional $\mathrm{kg}$ of car capacity and 28.62 DKK for one additional engine horsepower.

Table 5 reports logit estimation results for the car automatic transmission system. For every year, the car owner's willingness to accept an increase in total annual variable costs for the automatic transmission system rises by about 175 DKK. Males and households with children are willing to accept an increase in annual variable costs of 3,551 DKK and 7,470 DKK, respectively, to own a car with the automatic transmission system.

Table 5. Logit estimate for the marginal rate of substitution between automatic transmission system and variable cost

\begin{tabular}{|c|c|}
\hline & $\begin{array}{l}\text { Automatic } \\
\text { transmission }\end{array}$ \\
\hline Age & $\begin{array}{l}0.011^{* *} \\
(0.048)\end{array}$ \\
\hline Dummy indicating male & $\begin{array}{l}0.223^{* *} \\
(1.030)\end{array}$ \\
\hline Dummy indicating presence of children & $\begin{array}{l}0.469 * * * \\
(2.150)\end{array}$ \\
\hline Dummy indicating population density $1-1,000$ & $\begin{array}{l}0.045 \\
(0.256)\end{array}$ \\
\hline Dummy indicating population density $1,000-10,000$ & $\begin{array}{l}-0.132 \\
(0.624)\end{array}$ \\
\hline Dummy indicating population density $10,000-100,000$ & $\begin{array}{l}0.033 \\
(0.208)\end{array}$ \\
\hline Constant & $\begin{array}{l}-4.110^{* * *} \\
(17.700)\end{array}$ \\
\hline $\begin{array}{l}\text { R-square } \\
\text { No. observations }\end{array}$ & $\begin{array}{l}0.7351 \\
10,000\end{array}$ \\
\hline $\begin{array}{l}\text { Notes: We have normalized the coefficient on implic } \\
\text { performed with Biogeme (Bierlaire, } 2005) \text {. Omitted va } \\
\text { area with the highest population density in Denmark. * } \\
0.05 \text { and the } 0.10 \text { level, respectively. Standard errors ar }\end{array}$ & $\begin{array}{l}\text { 1. The estimat } \\
y \text { is the Copen } \\
\text { ro at the } 0.01 \text {, }\end{array}$ \\
\hline
\end{tabular}

Table 6 reports MNL estimation results for the car cabin indices. Notice here that hatchback is the omitted variable in the hedonic price functions. The mrs associated with a station car decreases with the car owner's age (for every year by $526 \mathrm{DKK}$ ). Moreover, males and households with children prefer hatchbacks compared to other car cabin types, while the average Danish household prefers a station car. 
Table 6. MNL for the marginal rate of substitution between car cabin types and variable cost

\begin{tabular}{|c|c|c|c|c|}
\hline & MPV & Sedan & Station car & Other \\
\hline \multirow[t]{2}{*}{ Age } & -0.002 & 0.003 & $-0.033^{* * *}$ & -0.017 \\
\hline & $(0.006)$ & $(0.006)$ & $(0.046)$ & $(0.027)$ \\
\hline \multirow[t]{2}{*}{ Dummy indicating male } & $-0.490 * * *$ & $-1.680 * * *$ & $-1.350 * * *$ & $-0.826 * * *$ \\
\hline & $(0.689)$ & $(2.340)$ & $(1.880)$ & $(1.180)$ \\
\hline \multirow[t]{2}{*}{ Dummy indicating presence of children } & $-1.430 * * *$ & $-0.639 * * *$ & $-0.814^{* * *}$ & $-1.600 * * *$ \\
\hline & $(1.990)$ & $(0.897)$ & $(1.140)$ & $(2.240)$ \\
\hline \multirow[t]{2}{*}{ Dummy indicating population density $1-1,000$} & $-0.511^{* * *}$ & $-0.317^{* *}$ & 0.096 & 0.118 \\
\hline & $(0.725)$ & $(0.466)$ & $(0.194)$ & $(0.378)$ \\
\hline \multirow[t]{2}{*}{ Dummy indicating population density $1,000-10,000$} & $-0.391 * *$ & -0.137 & $-0.268^{*}$ & $-0.709 *$ \\
\hline & $(0.566)$ & $(0.246)$ & $(0.403)$ & $(1.060)$ \\
\hline \multirow[t]{2}{*}{ Dummy indicating population density $10,000-100,000$} & 0.001 & 0.032 & 0.056 & -0.383 \\
\hline & $(0.163)$ & (0.169) & $(0.179)$ & $(0.677)$ \\
\hline \multirow[t]{2}{*}{ Constant } & $-0.999 * * *$ & $-1.430 * * *$ & $0.574^{* *}$ & $-3.470 * * *$ \\
\hline & $(1.410)$ & $(1.990)$ & $(0.795)$ & $(4.850)$ \\
\hline R-square & 0.2570 & 0.2570 & 0.2570 & 0.2570 \\
\hline No. observations & 10,000 & 10,000 & 10,000 & 10,000 \\
\hline
\end{tabular}

\section{Conclusion}

In this paper we have developed a model for choice of durable goods when variable costs are affected by quality attributes. This issue is ignored in the conventional hedonic analysis of, for instance, housing choice which restricts attention to the impact of quality attributes on fixed cost. Existing literature that considers fixed as well as variable costs concentrates on energy efficiency and the associated trade-off between fixed and variable costs. We concentrate on cases in which the quality attributes have a direct impact on utility and are positively related to fixed as well as variable costs. We developed a simple model that reduces to the standard two-good textbook model when quality is given. In this model quality attributes can be an argument of the utility function, while they also affect variable and fixed cost. The model covers situations in which variable costs are independent of quality attributes, or in which quality attributes affect variable and fixed costs in opposite ways as special cases. We showed that under plausible assumptions the second order condition for an interior solution is satisfied in market equilibrium where fixed costs (prices) have adjusted so as to equilibrate supply and demand for all quality levels.

We applied the model to Danish data. In these data fixed costs were positively related to variable cost even after controlling for car characteristics. Variable car costs were shown to be a substantial part of the total marginal cost of engine power and cabin capacity. We computed the total marginal willingness to pay for car characteristics. The distribution of this total willingness to pay was much smoother than that of its two cost components: marginal fixed cost and marginal variable cost. Marginal variable costs are on average about $20 \%$ of 
the full variable cost.

Finally, we related the marginal willingness to pay to household characteristics. Interesting correlations were found, and a structural interpretation of these results is possible if one is willing to make some additional assumption on the utility function.

\section{Acknowledgements}

The authors thank Mogens Fosgerau and Bruno de Borger for helpful discussions on earlier versions of this paper and Alexandros Dimitropoulos, Piet Rietveld and Jos van Ommeren for comments. We are grateful to Statistics Denmark and the Danish car dealer association (Danmarks Automobilforhandler Forening) for providing the data. Research support from the Danish Energy Agency (Energy Research Programme) is acknowledged.

\section{Appendix}

\section{Appendix A. Demand for car kilometers is increasing in car quality}

To elaborate this, consider a consumer whose optimal $q$ is $q^{\wedge}$ at the initial quality level $k$ and reaches a utility level $u^{\wedge}$ in that situation. That is, the solid budget line is tangent to the indifference curve corresponding to $u^{\wedge}$ at $q^{\wedge}$ (see Figure A1). If quality increases, say to $k^{\wedge}$, the indifference curve corresponding to $u^{\wedge}$ shifts downwards. The slope of the shifted indifference curve at $q=q^{\wedge}$ is now steeper, as is indicated by the dashed budget line. For $q=q^{\wedge}$ there is now another indifference curve, corresponding to a higher level of utility than $u^{\wedge}$, say $u^{\wedge}$ that crosses the budget line (see the dashed indifference curve in the graph). Since demand for $q$ is normal, the slope of this indifference curve must be steeper than the slope of the indifference curve corresponding to $u^{\wedge}$ at the higher quality level, and hence steeper than that of the indifference curve corresponding to $u^{\wedge}$ at the original quality level. In the graph, this means that the dashed indifference curve is steeper at $q=q^{\wedge}$ than the dashed budget line. And since the dashed budget line is steeper than the solid budget line, this implies that the dashed indifference curve crosses the solid budget line at $q^{\wedge}$ from above. In other words: the slope of the indifference curve that crosses the budget line at $q=q^{\wedge}$ gets steeper when quality increases and all else remains equal. The optimal $q$ will therefore be higher than $q^{\wedge}$ after the increase in quality. 
Figure A1. Car kilometers are increasing in quality

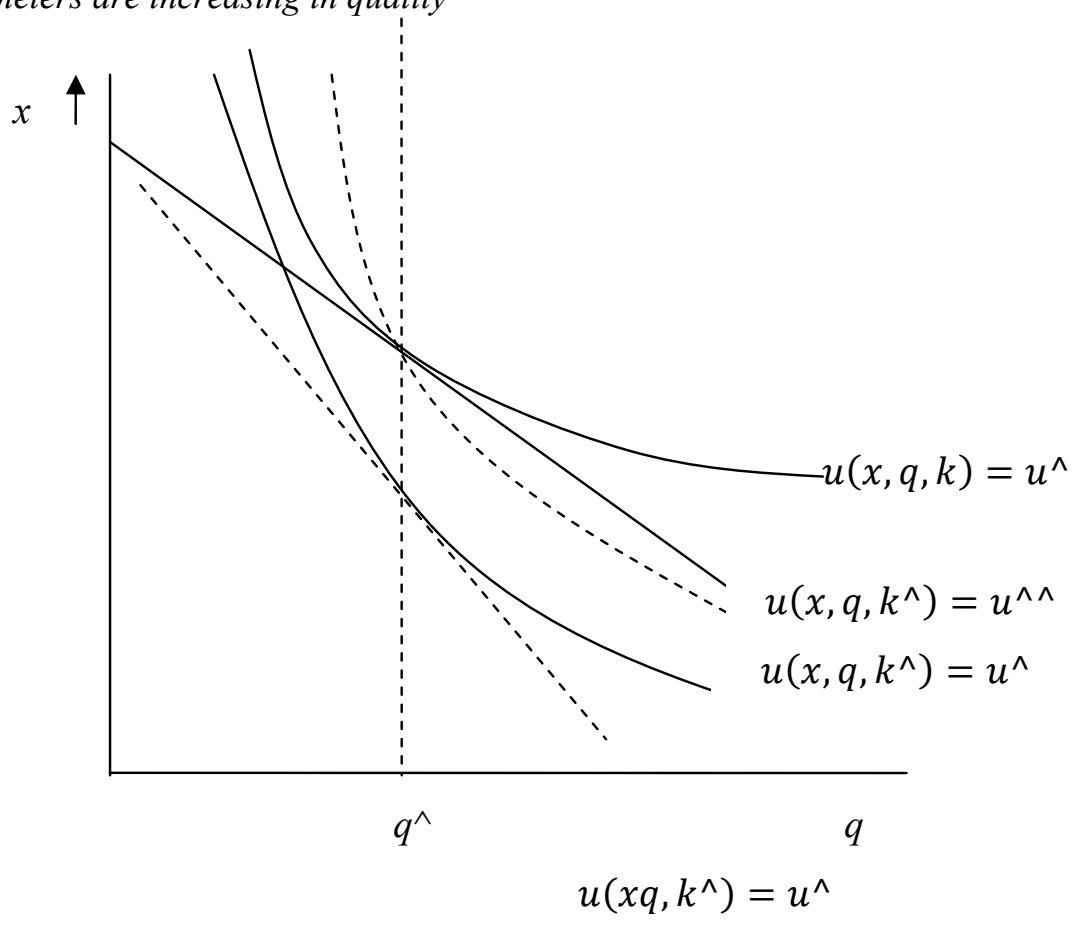

\section{Appendix B. Fixed costs in market equilibrium}

We adopt a short run perspective in which a given stock of - new and second hand - cars has to be distributed over a given number of households. The cars differ only in quality, which is here treated as a scalar variable, and the distribution of quality in the stock is a continuous function $G(k)$ that has positive support on $K$. Households all have the same tastes and differ only in income $y$. The income distribution is $H(y)$, and has positive support on a closed interval $\left[y^{\min }, y^{\max }\right]$. The total number of households is $H\left(y^{\max }\right)$. The total number of cars is $G\left(k^{\max }\right)$, which is assumed to be smaller than the number of households $\left(G\left(k^{\max }\right)<\right.$ $\left.H\left(y^{\max }\right)\right)$. An equilibrium in the market is a fixed cost function $f(k)$ that allows all consumers to realize their utility maximizing quality choice and allocates all cars to households.

We conjecture that in equilibrium consumers with higher incomes drive higher quality cars while the households with the lowest incomes do not own a car. Denoting the critical income level, at which a consumer is just indifferent between owning and not owning a car as $y^{*}$, we must then have:

$H(y(k))-H\left(y^{*}\right)=G(k)$. 
This equation implicitly defines $y(k)$ as the income level to which car quality $k$ must be allocated in equilibrium $\left(y(k)=y^{*}+H^{-1}(G(k))\right)$. In other words, $y(k)$ gives us the allocation of cars over households that must be realized in equilibrium.

This allocation rule should be supported by utility maximization of all consumers faced with a fixed cost function $f(k)$ that is as yet unknown. For all these consumers the first order condition (2.10) must hold at the allocation described by $y(k)$ :

$\frac{\partial f}{\partial k}=q(y(k)-f(k), p(k), k)\left(\operatorname{mrs}(y-f(k), p(k), k)-\frac{\partial p}{\partial k}\right)$

This equation repeats (2.10), after substitution of $y(k)$ for $y$, and makes all arguments of the demand and $m r s$ function explicit.

(B2) is a differential equation in $f(k)$. Its solution gives us the fixed cost function associated with market equilibrium, provided the second order condition is satisfied for all consumers. We can find a solution to (B2) by interpreting it as an initial value problem. Start by observing that we must have:

$y\left(k^{\min }\right)=y^{*}$.

That is, the consumer with the critical income level chooses the car with the lowest quality. This consumer must - by the definition of the critical income - be indifferent between owning and not owning a car. This provides us with the value of $f\left(k^{\min }\right)$. For instance, if consumers who do not own a car use public transport, which has zero fixed cost, variable cost $p^{p t}$ and quality $k^{p t}$, the utility of a such a consumer with income $\mathrm{y}$ is $v\left(y, p^{p t}, k^{p t}\right)$. If consumer with income $y^{*}$ is indifferent between car ownership and the use of public transport we must have:

$v\left(y^{*}, p^{p t}, k^{p t}\right)=v\left(y^{*}-f\left(k^{\min }\right), p\left(k^{\min }\right), k^{\min }\right)$,

and the value of $f\left(k^{\min }\right)$ is determined implicitly by this equation.

Once we know $f\left(k^{\min }\right)$, we can compute $\partial f\left(k^{\min }\right) / \partial k$ by substituting $f\left(k^{\text {min }}\right)$ into the right-hand-side of $(\mathrm{B} 2)$. The next step is to approximate $f\left(k^{\min }+\Delta\right)$ for a small value of $\Delta$ as: $f\left(k^{\min }+\Delta\right)=f\left(k^{\text {min }}\right)+\Delta \frac{\partial f\left(k^{m i n}\right)}{\partial k}$. We can then compute $\partial f\left(k^{\text {min }}+\Delta\right) / \partial k$ by substituting $f\left(k^{\min }+\Delta\right)$ into the right-hand side of (B2) (also using $y\left(k^{\min }+\Delta\right)$ instead of $y\left(k^{\min }\right)$ and continue the procedure until we reach $k^{\max }$.

This procedure is an application of the Euler method for solving differential equations, which is known to converge to the true solution of the differential equation for $\Delta \rightarrow 0$. General conditions for existence and uniqueness of a solution $f(k)$ are provided by the 
Picard-Lindelöf theorem. Essentially what is needed is that the function $f$ satisfies a Lipschitz condition.

\section{An illustration}

A closed form solution for the fixed cost function can be reached if we assume that all consumers have an indirect utility function (2.17). Here we assume that the parameters of this function are identical for all consumers (only incomes are different). Moreover, we assume that the variable cost is a linear function of quality:

$p(k)=\pi_{0}+\pi_{1} k$,

and that $\pi_{1}<-\frac{\delta}{\beta}$ to satisfy Assumption 3. Substituting the appropriate expressions into (B2) gives the following differential equation:

$\frac{\partial f}{\partial k}=\left(\alpha+\beta\left(\pi_{0}+\pi_{1} k\right)+\gamma(y(k)-f(k))+\delta k\right)\left(-\frac{\delta}{\beta}-\pi_{1}\right)$.

If the distributions of income and car quality are both uniform, then:

$G(k)=\frac{k-k^{\min }}{k^{\max }-k^{\min }}$,

$H(y)-H\left(y^{*}\right)=\frac{y-y^{*}}{y^{\max }-y^{*}}$.

Using these distributions, we can solve for $y(k)$ as: ${ }^{22}$

$y(k)=y^{*}+\left(k-k^{\min }\right)\left(\frac{y^{\max }-y^{*}}{k^{\max }-k^{\min }}\right)$.

After substitution of this result we can solve (B6) for $f(k)$ as:

$$
\begin{aligned}
f(k)= & \left(\left(k-k^{\text {min }}\right) C+y^{*}+\frac{\alpha+\beta\left(\pi_{0}+k \pi_{1}\right)+\delta k}{\gamma}+\frac{\beta}{\gamma^{2}}+\frac{\beta C}{\gamma\left(\delta+\beta \pi_{1}\right)}\right) \\
& +e^{\left(k-k^{\text {min }}\right) \gamma\left(\delta+\beta \pi_{1}\right) / \beta}\left(f\left(k^{\text {min }}\right)-y^{*}-\frac{\alpha+\beta\left(\pi_{0}+k^{m i n} \pi_{1}\right)+\delta k^{m i n}}{\gamma}-\frac{\beta}{\gamma^{2}}-\frac{\beta C}{\gamma\left(\delta+\beta \pi_{1}\right)}\right)
\end{aligned}
$$

In this equation $C$ denotes $\left(y^{\max }-y^{*}\right) /\left(k^{\max }-k^{\min }\right)$. Note that $\delta+\beta \pi_{1}>0$, because of assumption 3. This says that the positive effect of increased quality on car kilometers is larger than the negative price effect that occurs through the increase in variable costs associated with the higher quality.

The first expression in large parentheses in (B.10) is linear in $k$. Its slope is $C+$ $\frac{\delta+\beta \pi_{1}}{\gamma}$, which is positive. The second expression in large parentheses - that appears after the exponent - can be rewritten as:

$-\frac{1}{\gamma^{2}}\left[\beta+\left(\alpha+\beta\left(\pi_{0}+k^{\min } \pi_{1}\right)+\gamma\left(y^{*}-f\left(k^{\min }\right)\right)+\delta k^{\min }\right) \gamma\right]-\frac{\beta C}{\gamma\left(\delta+\beta \pi_{1}\right)}$.

${ }^{22}$ Recall from the discussion following (B.1) that $y(k)=y^{*}+H^{-1}(G(k))$. 
The expression in square brackets is the Slutsky term, which must be negative. The term (B.11) as a whole is therefore positive.

We conclude that the function is the sum of an upward sloping linear curve and a nonlinear term that decreases asymptotically to zero. It can be shown that whenever

\section{Appendix C. Additional information about the data}

Figure $\mathrm{C} 1$. Histogram and estimated kernel distribution of the number of kilometers driven $(\mathrm{km})$

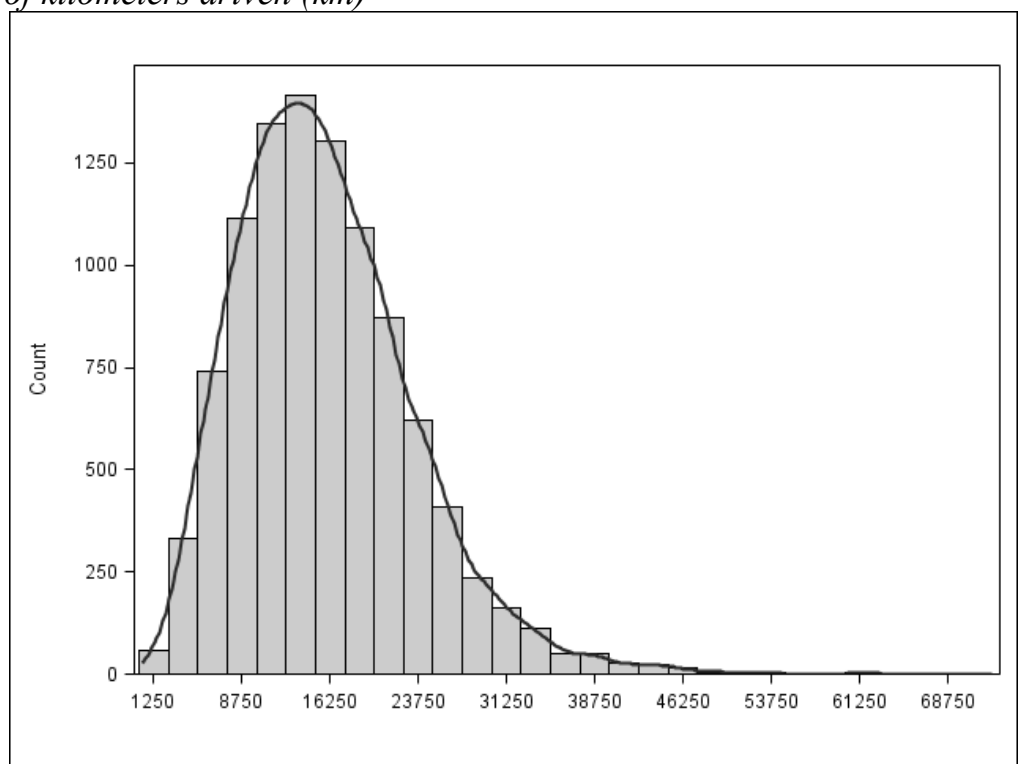

Notes: The Kernel density estimation is performed here using SAS KDE procedure (SAS Institute Inc., 2009). Mean value is 15,927 and standard deviation is 7,618. Bandwidth is 1,105 . Number of observations is 10,000 .

Table C.1. Summary statistics for the willingness to pay measures for the average car

\begin{tabular}{lrrrr}
\hline Variable & Mean & Std. Dev. & Minimum & Maximum \\
\hline Marginal willingness to pay (DKK) & 37,578 & 14,761 & 14,563 & 135,586 \\
Marginal fixed costs (DKK) & 29,409 & 12,023 & 13,283 & 110,134 \\
Marginal variable costs (DKK/km) & 0.5064 & 0.0712 & 0.3578 & 0.8719 \\
Marginal variable costs multiplied with the number of km driven (DKK) & 8,169 & 4,293 & 108 & 41,556 \\
\hline
\end{tabular}

Notes: The average car in this context is a Toyota sedan with manual transmission system, 99 horsepower, and the capacity of 521 kilograms. Number of observations is 10,000 .

Table C.2. Correlation matrix of $w t p, m f c, m v c$ and $q$

\begin{tabular}{lccc}
\hline & $\mathrm{q}$ & wtp & $\mathrm{mfc}$ \\
\hline wtp & 0.56724 & & \\
$\mathrm{mfc}$ & 0.35577 & 0.96919 & \\
$\mathrm{mvc}$ & 0.19161 & 0.72125 & 0.72597 \\
\hline \multicolumn{4}{l}{ Notes: Pearson correlation. All the correlations are significant at the 0.01 level. } \\
Number of observations is & 10,000.
\end{tabular}




\section{References}

Altman, N. S., 1992. An introduction to kernel and nearest-neighbor nonparametric regression, The American Statistician, 46, no. 3, 175-185.

Anglin, P. M. and Gencay, R., 1996. Semiparametric estimation of a hedonic price function, Journal of Applied Econometrics, 11, 633-648.

Bajari, P. and Kahn, M. E., 2005. Estimating housing demand with an application to explaining racial segregation in cities, Journal of Business \& Economic Statistics, 23, no. 1, 20-33.

Bajari, P. and Benkard, C. L., 2002. Demand estimation with heterogeneous consumers and unobserved product characteristics: a hedonic approach, working paper, Stanford University.

Berry, S., Levinsohn, J. and Pakes A., 1995. Automobile prices in market equilibrium. Econometrica, 63, 841-890.

Bierlaire, M., 2005. An introduction to biogeme (version 1.4), biogeme.epfl.ch.

Court, A. T., 1939. Hedonic price indexes with automotive examples, in the Dynamics of automobile demand, General Motors Corporation, New York, 99-117.

DAF, 2005, Brugtbilkatalog nr. 184, Danmarks Automobilforhandler Forening, Tåstrup.

Dagsvik, J. K. and Liu, G., 2009. A framework for analyzing rank-ordered data with application to automobile demand, Transportation Research Part A, vol. 43, 1-12.

Dubin, J. and McFadden, D., 1984. An econometric analysis of residential electric appliance holding and consumption, Econometrica 52, 345-362.

Fan, J and Gijbels, I., 1996, Local polynomial modeling and its applications, Chapman \& Hall, London.

FDM, 2009, Beregningseksempel fra Motor nr. 12009 , http:/www.fdm.dk/filer/ Beregningseksempel.pdf, (accesed 24/10 2010).

Griliches, Z., 1961. Hedonic price indexes for automobiles: an econometric analysis of quality change' mimeo, NBER.

Hausman, J., 1979. Individual discount rates and the purchase and utilization of energy-using durables, The Bell Journal of Economics, 10, 33-54.

Hausman, J., 1981. Exact consumer's surplus and deadweight loss. American Economic Review, 71, 662-676.

Huber, P.J., 1973. Robust regression: asymptotics, conjectures and monte carlo, The Annals of Statistics, 1, no. 5, 799-821. 
Härdle, W., 1993. Applied nonparametric regression, Cambridge University Press.

Mas-Colell, A., Whinston, M. D. and Green, J. R., 1995. Microeconomic Theory, Oxford University Press.

McMillen, D. 2010 'Issues in spatial data analysis', forthcoming in the Journal of Regional Science.

Pace, R. K., 1995. Parametric, semiparametric, and nonparametric estimation of characteristics values within mass assessment and hedonic pricing models, Journal of Real Estate Finance and Economics, 11, 195-217.

Rosen, S., 1974. Hedonic prices and implicit markets: product differentiation in perfect competition, Journal of Political Economy, 82, 34-55.

SAS Institute Inc., 2009. SAS/STAT® 9.2 User’s guide second edition, Cary, NC

www.bilpriser.dk, Mikrobilsanalysen 2009, http://www.bilpriser.dk/analyselist.do (accesed 24/10 2010).

— Småbilsanalysen 2009, http://www.bilpriser.dk/analyselist.do (accesed 24/10 2010).

- Mellemklasseanalysen 2009, http://www.bilpriser.dk/analyselist.do (accesed 24/10 2010).

- Stationcarsanalysen 2009, http://www.bilpriser.dk/analyselist.do (accesed 24/10 2010).

- MPV-analysen 2009, http://www.bilpriser.dk/analyselist.do (accesed 24/10 2010).

- Cabrioletanalysen 2009, http://www.bilpriser.dk/analyselist.do (accesed 24/10 2010).

Sheppard, S., 1999. Hedonic analysis of housing markets, in Handbook of Regional and Urban Economics, eds. P. Cheshire and S. Mills, Volume 3, Chapter 41, pp. 1595-1635. 